\title{
Clinical significance of serum PSA in breast cancer patients
}

\author{
Toru Hanamura ${ }^{1,2,3^{*}}$ (D), Koichi Ohno ${ }^{1,2}$, Shinya Hokibara ${ }^{4}$, Hideki Murasawa ${ }^{5}$, Toshitsugu Nakamura ${ }^{4}$, \\ Hidehiko Watanabe ${ }^{6}$, Machiko Kaizuka ${ }^{7}$, Shinji Sawano ${ }^{8}$, Hiroshi Koyama ${ }^{9}$ and Ken-ichi Ito $^{2}$
}

\begin{abstract}
Background: Recent preclinical data suggest that androgen receptor (AR) signaling plays a significant role in subsets of breast cancer. Clinical trials testing AR-targeting therapies in breast cancer have been conducted. Assessment of AR-signal in breast cancer tissue maybe useful for treatment selections. Prostate specific antigen (PSA) is the product of an androgen-responsive gene. Serum PSA (SPSA) can be detected in women by a highly sensitive assay although the concentration is much lower than that observed in males. We investigated if SPSA reflects tumor biology, including AR signaling in breast cancer patients.
\end{abstract}

Methods: In this study, 132 healthy controls and 144 breast cancer patients were enrolled. sPSA was evaluated by the chemiluminescent enzyme immunoassay (CLEIA) method. Correlations between SPSA and the various clinicopathological factors were analyzed.

Results: In post-menopausal state, SPSA detection rate was significantly higher in breast cancer patients compared with controls (27.4\% vs 11.3\%: $p=0.0090)$, but not in the whole cohort $(29.2 \%$ vs $25.8 \%$ : $p=0.5265)$ or pre-menopausal subgroup (37.0\% vs 42.6\%: $p=0.6231$ ). In post-menopausal breast cancer cases, higher sPSA value was associated with clinic-pathological factors including the expression of AR protein in primary legion. In a correlation analysis of quantitative data limited to post-menopausal metastatic breast cancer (MBC), sPSA was positively, albeit weakly correlated with clinic-pathological features including serum testosterone levels and AR positivity.

Conclusions: Our data suggest that sPSA may reflect tumor biological properties including AR activity in postmenopausal breast cancer.

Keywords: Breast cancer, Androgen signal, Androgen receptor, PSA

\section{Background}

Breast cancer is the most common malignancy in women worldwide and one of the leading causes of cancer death. While specific therapeutics have been developed and treatment outcomes have improved, about a third of patients treated for apparently localized breast cancer develop metastatic disease [1-3]. Therefore, it is necessary to further improve the outcome of initial treatment and to develop more effective treatment strategies for recurrent, metastatic disease.

\footnotetext{
* Correspondence: hanamuratooru@hotmail.co.jp

'Department of Breast and Endocrine Surgery, Suwa Red Cross Hospital, 5-11-50, Kogan-dori, Suwa, Nagano 392-8510, Japan

2Division of Breast and Endocrine Surgery, Department of Surgery, Shinshu University School of Medicine, 3-1-1 Asahi, Matsumoto, Nagano 390-8621, Japan

Full list of author information is available at the end of the article
}

The majority of breast cancers are hormone-dependent and estrogen deprivation therapy is the major treatment strategy [1,2]. Although in the adjuvant setting, women can be treated with selective estrogen receptor modulators (SERMs) or aromatase inhibitors (AIs), some patients exhibit de novo resistance and some develop acquired resistance over time [1-4]. Recently, to model AI-resistant breast cancer we generated variant cell lines from the estrogen receptor (ER)-positive T-47D breast carcinoma cell line under estrogen-depleted, excess androgen conditions. These variant cell lines had increased androgen receptor (AR) and exhibited decreased expression of ER and no growth response to estrogen. Furthermore, androgen markedly induced proliferation in these cell lines [5-7]. In another study, AR overexpression led to tamoxifen resistance in in vitro models of breast cancer, implicating the

(c) The Author(s). 2019 Open Access This article is distributed under the terms of the Creative Commons Attribution 4.0 International License (http://creativecommons.org/licenses/by/4.0/), which permits unrestricted use, distribution, and reproduction in any medium, provided you give appropriate credit to the original author(s) and the source, provide a link to the Creative Commons license, and indicate if changes were made. The Creative Commons Public Domain Dedication waiver (http://creativecommons.org/publicdomain/zero/1.0/) applies to the data made available in this article, unless otherwise stated. 
involvement of AR signaling in tamoxifen resistance [8]. Therefore, it is hypothesized that a possible resistance mechanism could be tumor adaptation from ER dependence to AR dependence [4, 9-11]. AR-targeting therapies for ER-positive breast cancer (NCT02910050 for bicalutamide, NCT01597193, NCT02955394, NCT02953860, NCT02007512 for enzalutamide, respectively) are currently being conducted.

AR dependency has also been suggested in a subset of ER-negative, AR-positive breast cancers [12-15]. Triple negative breast cancer (TNBC) is defined by the lack of estrogen and progesterone receptors as well as an absence of HER2 (human epidermal growth factor receptor 2) amplification. Because of the lack of specific targeted therapy, $30-40 \%$ of patients with early-stage TNBC develop metastatic disease and succumb to the cancer, despite receiving standard multi-agent adjuvant chemotherapy [16, 17]. Both molecular and immunohistochemical analyses demonstrate that a subset of TNBC expresses AR. Recently, numerous preclinical studies have validated the use of AR modulation in limiting cell proliferation, growth on soft agar, and tumor initiation in vivo $[14,15,18-20]$ and there are ongoing clinical trials evaluating the efficacy of AR antagonists in ERnegative breast cancer (NCT00468715, NCT03055312, NCT03090165, NCT02605486 for bicalutamide, NCT02750358, NCT02689427, NCT01889238, NCT02457910 for enzalutamide, respectively).

AR functions as a transcription factor upon binding to androgen, and regulates the transcription of target genes [21]. Because AR signaling plays pivotal roles in prostate cancer, AR targeting therapies are widely used for prostate cancer treatment [22]. Prostate specific antigen (PSA) is a serine protease encoded in humans by the kallilrein related peptidase 3 (KLK3) gene [23]. The transcription of the $K L K 3$ gene is positively regulated by AR [21]. Therefore, PSA is one of the most widely used serum biomarkers for the diagnosis and follow-up of prostate cancer [24]. Although widely thought to be exclusively produced in prostate gland [25], extra-prostatic production of PSA has been reported in various conditions including normal breast tissue and benign and malignant breast tumors [26]. Furthermore, it was reported that serum PSA (sPSA) can be detected in breast cancer patients by highly sensitive assay [23, 27, 28]. If sPSA levels reflect the amount of AR signaling or AR dependency of the tumor in breast cancer patient, it may be useful for effective treatment selection. However, its biological significance in relation to breast cancer has not been established.

In this study, we investigated whether sPSA might reflect tumor biology, including AR signaling. Using blood samples from both healthy controls and breast cancer patients, individuals were enrolled regardless of age, clinicopathological factor or treatment history. sPSA was evaluated by chemiluminescent enzyme immunoassay (CLEIA) method at various timepoints for each case. Then correlations between sPSA and clinicopathological factors were analyzed.

\section{Methods}

This study was conducted in Suwa Red Cross Hospital, Suwa Central Hospital, Okaya City Hospital and Koyama Clinic during August 2017 to January 2018. All procedures performed in this study involving human participants were conducted with approval of the Suwa Red Cross Hospital ethics committee (reference number: 2940) in accordance with the ethical standards of the institutional research committee and with the 1964 Helsinki declaration and its later amendments. Written informed consent was obtained from all participants for protocols including blood collection, reviewing case records and use of archival samples.

\section{Subjects}

Breast cancer patients, with the exception of cases without relapse after surgery, were enrolled regardless of age, clinicopathological factor or treatment history. Preoperative stage 0 - III, de novo stage IV and recurrent breast cancer cases were included. Healthy women who performed a mammography examination in annual general checkup were enrolled as healthy controls. Due to the short period of the study, it was not possible to match breast cancer patients and healthy controls by age or menopause status. It is reported that SPSA may show higher values in benign breast disease including mammary cysts and fibroadenoma [26]. However, since the purpose of this analysis was not to verify whether sPSA is a marker for breast cancer detection or discrimination of malignancy from benign breast disease, but to determine whether sPSA reflects breast cancer biological characteristics, patients with benign breast disease were excluded from this analysis. Women with current morbidity or history of uterine fibroids, polycystic ovary syndrome, benign ovarian tumor, hirsutism, malignancy other than breast cancer, use of oral contraceptive and hormone replacement therapy were also excluded regardless of breast cancer group or healthy control group in this study, because these diseases are reported to have higher sPSA values [26]. Breast cancer patients with only ipsilateral axillary recurrence or loco-regional recurrence were excluded. Women who had any abnormality in mammography were excluded from healthy controls.

\section{Data collection}

Clinical data including age, menopausal state, clinical stage, disease status and treatment history were collected by reviewing patient case records. At the time of blood 
sample collection, subjects who had amenorrheic for more than 1 year were defined as postmenopausal, whether this was natural or post-chemotherapy. All other subjects were defined as premenopausal. Clinical stage was assessed based on UICC TNM classification [29]. Anastrozole, letrozole, and exemestane were defined as AIs, tamoxifen and toremifene as SERMs, and fulvestrant as selective estrogen receptor degrader (SERD). Recurrence during adjuvant endocrine therapy or within 12 months after completion of adjuvant endocrine therapy and disease progression during treatment for metastatic disease were defined as drug resistant.

\section{Blood samples}

Blood samples from Stage 0 - III breast cancer patients other than patient who underwent pre-operative adjuvant chemotherapy were obtained within one month before surgery for primary lesion $(n=62)$. Blood samples from patients who underwent pre-operative adjuvant chemotherapy $(n=5)$ were obtained after the core needle biopsy of the primary lesion within one month before starting the chemotherapy. Blood samples from $\mathrm{MBC}$ including de novo stage IV and recurrent breast cancer patients were obtained before starting treatment $(n=12)$ or on treatment $(n=65)$ for metastatic disease. Blood samples were collected by venipuncture in a plain plastic tube. After centrifugation at $2000 \times \mathrm{g}$ for $7 \mathrm{~min}$; the sera were stored frozen $\left(-80^{\circ} \mathrm{C}\right)$ until analysis. At the start of the study, a pilot study was conducted for ten samples using five sPSA testing kits, and the kit which showed highest sPSA detection rate was selected for further study (Additional file 1 Table S1). Sandwichtype CLEIA was performed for serum total PSA quantitation according to the manufacturer's standard protocol using TOSOH PSA kit AIA pack CL (TOSOH CO., LTD., Tokyo, Japan). Briefly, the monoclonal antibody against PSA was immobilized on a microtiter plate and serum samples were added. After incubation at RT, the alkaline phosphatase-linked secondary antibody for PSA was added. After another incubation, DIFURAT ${ }^{\circledR}$ was added as substrate. Chemiluminescent was detected by the automated $\mathrm{AIA}^{\oplus}$-CL2400 platform ((TOSOH CO., LTD., Tokyo, Japan). The detection limit of immunoassays is $3 \mathrm{ng} / \mathrm{L}$. Intra-assay and inter-assay CVs are 2.0$3.1 \%$ and $3.2-3.7 \%$, respectively. For quantitation of serum estradiol and testosterone the competitive-type electrochemiluminescence immunoassay was performed according to the manufacturer's standard protocol using an Elecsys ${ }^{\oplus}$ Estradiol IV test kit and an Elecsys ${ }^{\oplus}$ testosterone II test kit (Roche, Basel, Switzerland), respectively. The detection limits for estradiol and testosterone are 5 $\mathrm{pg} / \mathrm{mL}$ and $0.025 \mathrm{ng} / \mathrm{mL}$, respectively. With regard to testing for sPSA, estradiol and testosterone, samples showing the value under the detection limit of each test were considered as inferior as this value, non-parametric tests were performed during statistical analysis including these test values. Values of 0 in the graph represent samples below the detection limit.

\section{Tumor samples}

Tumor samples from breast cancer patients, other than de novo stage IV, were obtained during surgery for primary lesion. In the case of de novo stage IV tumors, specimens were collected from the core needle biopsy of the primary tumor. All specimens were fixed with $10 \%$ formalin and embedded in paraffin wax.

Pathological data including histological type, ER / PgR / HER2 / Ki67 status and nuclear grade were collected by reviewing patient case records. ER, PgR, and HER2 statuses were evaluated by IHC staining. The cut-off value for ER and PgR positivity was set at $\geq 1 \%$ [30]. Tumors were considered to overexpress HER2 if they were given a score of 3 following IHC staining, or if they showed $\geq 2.0$-fold amplification of the HER2 gene, as assessed by fluorescence in situ hybridization (FISH). FISH testing was only performed for tumors that scored 2 during IHC staining [31]. The cut-off value of Ki67 was set at $20 \%$ in this study [32]. The nuclear grade composed of nuclear atypia and mitotic counts were evaluated based on the Japanese Classification of Breast Cancer [33, 34].

Expression of AR and PSA in primary lesion was evaluated by IHC method using archival samples. Mouse monoclonal antibodies for AR (clone AR441) and PSA (clone 35H9) were purchased from Agilent Technologies (Santa Clara, CA, USA) and Leica Biosystems (Wetzlar, Germany), respectively. The IHC staining was performed using the Ventana Benchmark LT automated IHC device (Roche Diagnostics, Basel, Switzerland) and the reaction product was detected with Ventana iVIEW DAB Universal kit (Roche Diagnostics). The antigen-antibody complex was visualized with diaminobenzidine (DAB) and counter-stained with hematoxylin. AR immunoreactivity was detected in the nuclei of breast carcinoma cells, and the percentage of immunoreactive cells, i.e., labeling index (LI), was determined [18]. The median of AR LI, 20\%, was taken as the cut-off value for the AR expression. PSA immunoreactivity was considered positive if any cytoplasmic staining was observed in the carcinoma cells [5].

\section{Statistical analysis}

Statistical analyses were performed using the StatFlex 6.0 software program (Artech Co., Ltd., Osaka, Japan). In comparison between groups, sPSA-detected cases and non-detected cases were defined as SPSA positive and negative, respectively. Chi-squared test was used for comparison of these group. Spearman's rank correlation 
coefficient was applied for correlation between quantitative data and sPSA values using absolute values of sPSA but, for visualization, log-transformed values of sPSA were used for the graphs. Representative values of sPSA were shown in Median (Inter-quartile range). MannWhitney $U$ test or Kruskal Wallis test were used for comparison of sPSA among two group or multiple groups respectively. Samples with unknown values were excluded from the statistical analysis. Values of $P<0.05$ were considered statistically significant. Actual $p$ values are shown in figures for all of statistical testing.

\section{Results}

SPSA value in breast cancer patients and healthy controls In present study, 132 healthy controls (53.8\% were postmenopausal) and 144 breast cancer patients $(81.3 \%$ were postmenopausal) were enrolled. Characteristics of breast cancer cases and healthy controls are shown in Table 1. sPSA was detected in 29.2 and $25.8 \%$ of breast cancer patients and controls, respectively, with no statistically significant difference between groups. Similarly, there was no statistically significant difference in the levels of
sPSA between breast cancer patients and controls $(0[0$ 4.0] $\mathrm{ng} / \mathrm{L}$ vs 0 [0-3.0] $\mathrm{ng} / \mathrm{L} ; p=0.3409$ ). In subsequent analyses sPSA values from pre- and post-menopause subjects were separated. In pre-menopausal state, there was no significant difference in sPSA detection rate between breast cancer patients and controls $(37.0 \%$ vs 42.6\%: $p=0.6231)$. However, in the post-menopausal state sPSA detection rate was significantly higher in breast cancer patients compared with controls $(27.4 \%$ vs 11.3\%: $p=0.0090$ ). (Fig. 1, Table 2). Similar results were also obtained in the comparison of the levels of sPSA (Additional file 1 Table S2).

\section{SPSA value in post-menopausal breast cancer patients}

In analysis limited to post-menopausal breast cancer cases, sPSA detection rate was significantly higher in MBC compared with non-MBC $(36.1 \%$ vs $13.3 \%$ : $p=$ 0.0072). Similarly, sPSA detection rate was significantly higher in high AR ( $\geq 20 \%)$ cases compared with low AR $(<20 \%)$ cases $(39.0 \%$ vs $14.5 \%: p=0.0034)$. sPSA detection rate was higher in low Ki67 $(<20 \%)$ cases compared with high Ki67 ( $\geq 20 \%)$ (36.5\% vs 19.4\%: $p=0.0400)$.

Table 1 Clinical and histopathological characteristics of 132 healthy controls and 144 breast cancer patients

\begin{tabular}{|c|c|c|c|}
\hline & & $\begin{array}{l}\text { Healthy control } \\
(n=132)\end{array}$ & $\begin{array}{l}\text { Breast cancer } \\
(n=144)\end{array}$ \\
\hline & & No of cases (\%) & No of cases $(\%)$ \\
\hline Age $($ mean $\pm S D)$ & & $53.1 \pm 10.7$ & $62.9 \pm 13.2$ \\
\hline \multirow[t]{2}{*}{ Menopausal status } & Pre-menopausal & $61(46.2)$ & $27(18.8)$ \\
\hline & Post-menopausal & $71(53.8)$ & $117(81.3)$ \\
\hline sPSA detection rate & & $25.8 \%$ & $29.2 \%$ \\
\hline sPSA ng/l (Median [IQR $\left.\left.{ }^{*}\right]\right)$ & & $0(0-3)$ & $0(0-4)$ \\
\hline \multirow[t]{2}{*}{ Clinical stage } & Non-MBC; Stage 0-III & - & $67(46.5)$ \\
\hline & MBC; Stage IV, Recurrence & - & $77(53.5)$ \\
\hline \multirow[t]{5}{*}{ Histological type } & Invasive ductal carcinoma & - & $102(70.8)$ \\
\hline & Ductal carcinoma in situ & - & $9(6.3)$ \\
\hline & Invasive lobular carcinoma & - & $11(7.6)$ \\
\hline & Lobular carcinoma in situ & - & $0(0)$ \\
\hline & Special type & - & $22(15.3)$ \\
\hline \multirow[t]{4}{*}{ Subtype } & Luminal; ER+ / HER2- & - & $99(68.8)$ \\
\hline & Luminal HER2; ER+ / HER2+ & - & $16(11.1)$ \\
\hline & HER2 enriched; ER- / HER2+ & - & $8(5.6)$ \\
\hline & TNBC; ER- / HER2- & - & $21(14.6)$ \\
\hline \multirow[t]{3}{*}{ Histological grade } & 1 & - & $82(56.9)$ \\
\hline & 2 & - & $40(27.8)$ \\
\hline & 3 & - & $22(15.3)$ \\
\hline \multirow[t]{3}{*}{ Ki67 positivity } & $<20 \%$ & - & $60(41.7)$ \\
\hline & $\geqq 20 \%$ & - & $81(56.3)$ \\
\hline & Unknown & - & $3(2.1)$ \\
\hline
\end{tabular}




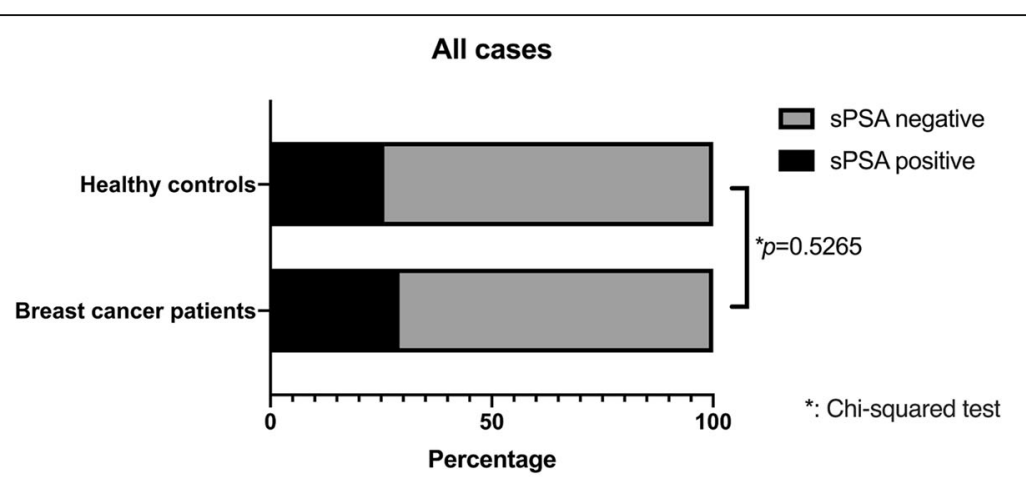

Pre-menopausal

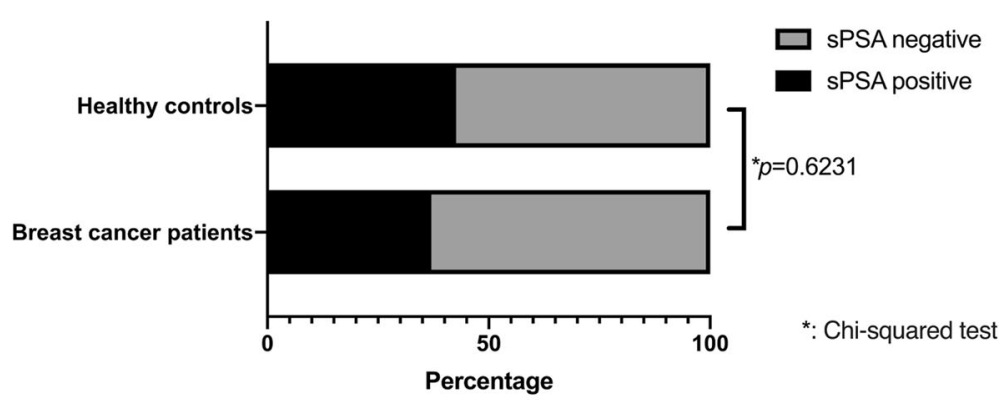

Post-menopausal

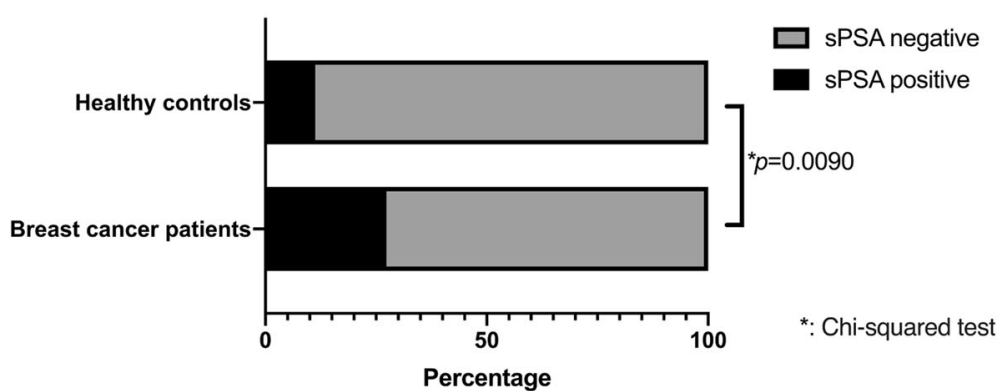

Fig. 1 Serum PSA detection rate in breast cancer patients and healthy controls $(n=276)$. The $X$ axis shows sPSA detection rate. The difference between two groups were analyzed by Chi-squared test. Values of $p<0.05$ were considered statistically significant

Table 2 sPSA detection rate in breast cancer patients and healthy controls

\begin{tabular}{|c|c|c|c|}
\hline & sPSA positive (\%) & sPSA negative (\%) & $p$ value \\
\hline \multicolumn{3}{|l|}{ All cases $(n=276)$} & \multirow[t]{3}{*}{0.5265} \\
\hline Healthy control & $34(25.8)$ & $98(74.2)$ & \\
\hline Breast cancer & $42(29.2)$ & $102(70.8)$ & \\
\hline \multicolumn{3}{|c|}{ Pre-menopausal cases $(n=88)$} & \multirow[t]{3}{*}{0.6231} \\
\hline Healthy control & $26(42.6)$ & $35(57.4)$ & \\
\hline Breast cancer & $10(37.0)$ & $17(63.0)$ & \\
\hline \multicolumn{3}{|c|}{ Post-menopausal cases $(n=188)$} & \multirow[t]{3}{*}{0.0090} \\
\hline Healthy control & $8(11.3)$ & $63(88.7)$ & \\
\hline Breast cancer & $32(27.4)$ & $85(72.6)$ & \\
\hline
\end{tabular}

There was no significant difference in sPSA detection rate due to histological type, tumor subtype, PSA expression by IHC and nuclear grade in primary lesion (Table 3). Similar results were also obtained in the comparison of the levels of sPSA (Additional file 1 Table S3).

\section{Correlation between SPSA and various clinicopathological} factors in post-menopausal MBC

We performed a correlation analysis of various quantitative data and sPSA in post-menopausal MBC cases, since these patients showed high sPSA values in the above analysis suggesting that sPSA of these patients are more likely to be derived from breast cancer tissue. In these patients, sPSA was weakly but positively correlated with age ( $\mathrm{rS}=0.25, p=0.0377)$, serum testosterone levels (ng/ ml) $(\mathrm{rS}=0.28, p=0.0178)$ and AR positivity (\%) $(\mathrm{rS}=$ $0.48 p<0.0001)$. Likewise, sPSA was negatively 
Table 3 sPSA detection rate in post-menopausal breast cancer patients $(n=117)$

\begin{tabular}{|c|c|c|c|c|}
\hline & $n$ & sPSA positive (\%) & sPSA negative (\%) & $p$ value \\
\hline Clinical stage & & & & 0.0072 \\
\hline Non-MBC; Stage 0-III & 45 & $6(13.3)$ & $39(86.7)$ & \\
\hline MBC; Stage VI, Recurrence & 72 & $26(36.1)$ & $46(63.9)$ & \\
\hline Histological type & & & & 0.9320 \\
\hline Invasive ductal carcinoma & 82 & $21(25.6)$ & $61(74.4)$ & \\
\hline Ductal carcinoma in situ & 6 & $2(33.3)$ & $4(66.7)$ & \\
\hline Invasive lobular carcinoma & 10 & $3(30.0)$ & $7(70.0)$ & \\
\hline Special type & 19 & $6(31.6)$ & $13(68.4)$ & \\
\hline Subtype & & & & 0.3028 \\
\hline Luminal; ER+ / HER2- & 83 & $19(22.9)$ & $64(77.1)$ & \\
\hline Luminal HER2; ER+ / HER2+ & 13 & $6(46.2)$ & $7(53.8)$ & \\
\hline HER2 enriched; ER- / HER2+ & 7 & $2(28.6)$ & $5(71.4)$ & \\
\hline TNBC; ER- / HER2- & 14 & $5(35.7)$ & $9(64.3)$ & \\
\hline Androgen receptor & & & & 0.0034 \\
\hline$<20 \%$ & 55 & $8(14.5)$ & $47(85.5)$ & \\
\hline$\geq 20 \%$ & 59 & $23(39.0)$ & $36(61.0)$ & \\
\hline Unknown & 3 & $1(33.3)$ & $2(66.7)$ & \\
\hline PSA (IHC of primary lesion) & & & & 0.1271 \\
\hline Positive & 64 & $21(32.8)$ & $43(67.2)$ & \\
\hline Negative & 50 & $10(20.0)$ & $40(80.0)$ & \\
\hline Unknown & 3 & $1(33.3)$ & $2(66.7)$ & \\
\hline Nuclear grade & & & & 0.7405 \\
\hline 1 & 67 & $18(26.9)$ & 49 (73.1) & \\
\hline 2 & 36 & $9(25.0)$ & $27(75.0)$ & \\
\hline 3 & 14 & $5(35.7)$ & $9(64.3)$ & \\
\hline Ki67 (LI) & & & & 0.0400 \\
\hline$<20 \%$ & 52 & $19(36.5)$ & $33(63.5)$ & \\
\hline$\geq 20 \%$ & 62 & $12(19.4)$ & 50 (80.6) & \\
\hline Unknown & 3 & $1(33.3)$ & $2(66.7)$ & \\
\hline
\end{tabular}

correlated with $\mathrm{Ki67}(\mathrm{rS}=-0.25, p=0.0178)$. sPSA did not correlate with the serum estrogen level, disease free interval, number of metastatic organs, number of previous chemotherapies the number of previous endocrine therapies or total number of therapies (Fig. 2).

\section{Difference in SPSA value due to previous endocrine therapy}

In the analysis limited to post-menopausal ER positive $\mathrm{MBC}$, although there was no statistical difference in SPSA detection rate due to resistance to AIs, SERMs or SERDs (Fig. 3, Table 4), AI-resistant cases have significantly higher sPSA levels compared with non-AI resistant cases (0 [0-29.5] ng/L vs 0 [0-1.0] ng/L; $p=0.0473$ ) (Additional file 1 Table S4). Although there were no statistically significant differences, sPSA detection rate and their levels tended to be higher in AI-resistant cases compared with
non-AI resistant cases, regardless of whether they were on AI therapy at the time of the blood sample collection (Fig. 4 and Additional file 2 Figure S1).

\section{Discussion}

As mentioned above, the recent use of ultrasensitive PSA immunoassays has enabled detection of PSA in normal female serum, even if at extremely low concentrations compared with that of males [35]. In the context of breast cancer, sPSA was reported to be higher in breast cancer patients compared with healthy control and decreased in the serum of breast cancer patients after surgery $[27,28]$ indicating that PSA derived from breast cancer tissues can be detected in serum. In our study, the above findings indicate that under normal physiological conditions sPSA was detectable before menopause and is low to non-detectable following menopause 


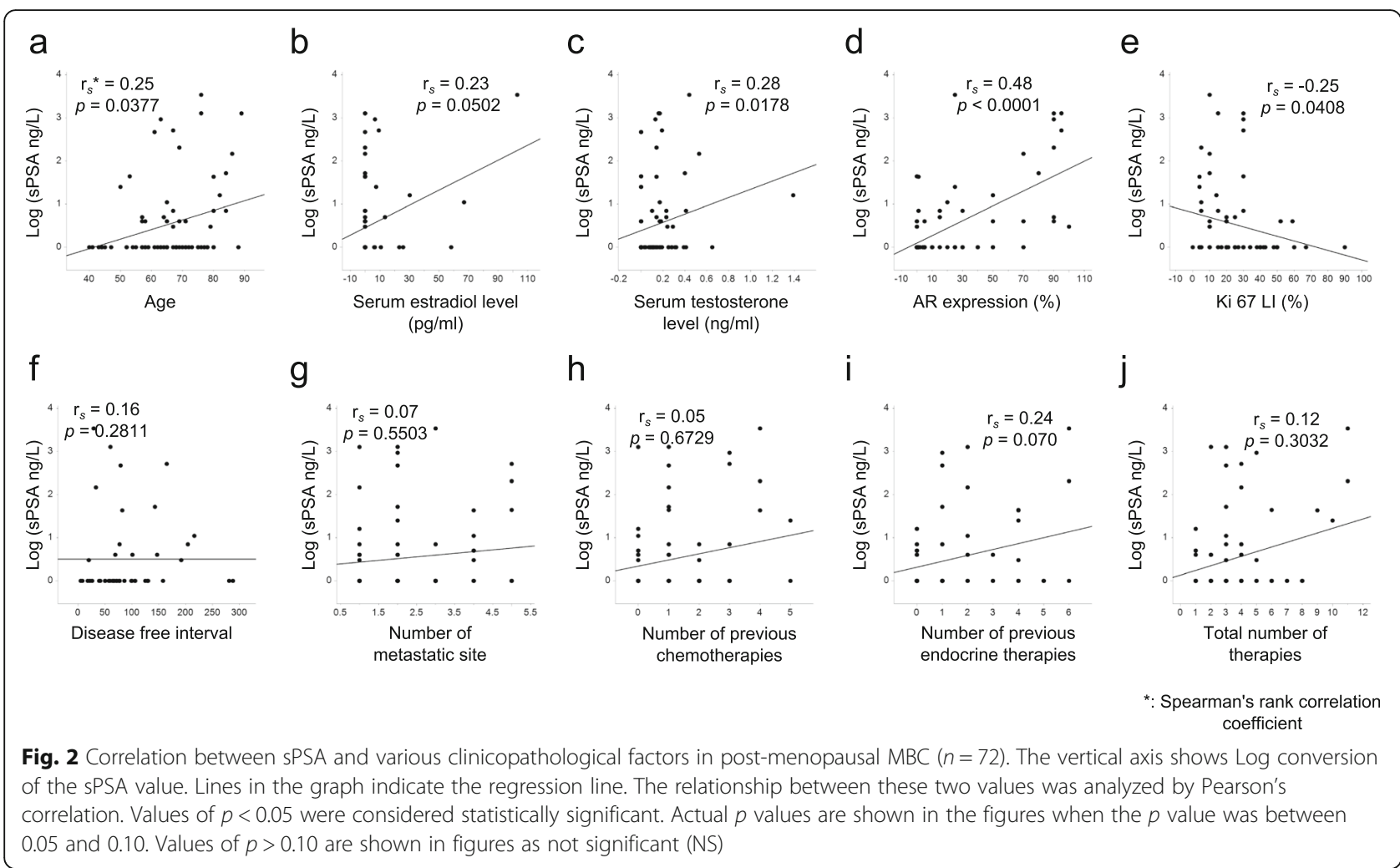

(Fig. 1, Table 2). Notably, in breast cancer patients sPSA was detected after menopause, which suggests that SPSA in these post-menopausal patients may be from the tumor itself. However, in this study there were no significant difference in sPSA between breast cancer patients and normal control in the global analysis except for post-menopausal women. This differs from previous reports showing the higher sPSA levels in both of preand post-menopausal breast cancer patients compared with control [36]. This may be due to the relatively few premenopausal cases. Therefore, further investigation is needed. Subsequent analyses were done only for the post-menopausal case. In addition, in the previous study $[27,28]$, sPSA levels are associated with younger age, premenopausal status regardless of health condition, and larger tumor size in breast cancer cases, which corresponds well with our results that sPSA was higher in the pre-menopausal state and in advanced disease, such as MBC (Fig. 1, Tables 2, 3). Although, in our study, sPSA values were under the detection limit in more than $70 \%$ of samples and showed large data deviation, similar trends were found in the other reports from Black et al. [27]. Existing research about sPSA in breast cancer had focused on its diagnostic value [27, 28, 36, 37]. Its correlation to biological features associated with breast cancer have not been fully established, especially in the context of the association of androgens or AR signaling. Therefore, this is the first study which analyzed in detail the relationships between sPSA and various biological characteristics of breast cancer and, in particular, the relation to serum androgen level and AR expression in the primary tumor tissue.

In our analysis limited to post-menopausal breast cancer cases, sPSA values were significantly higher in MBC (de novo stage IV and recurrence) compared with nonMBC (stage 0 - III) (Table 3). This seems to reflect the tumor volume rather than biological characteristics of the tumor. Black et al. reported that sPSA was significantly associated with larger breast tumor size [27]. The most interesting result was that sPSA was positively correlated with serum testosterone levels and AR positivity in post-menopausal MBC (Fig. 2) suggesting that sPSA might function as a readout of AR activity in tumors. On the contrary, tissue PSA expression in the primary tumor did not correlate with sPSA levels (Table 3). This may be because many cases were treated prior to blood sample collection, so tumor biological features might have changed with treatment. The evaluation of PSA by IHC in breast cancer has not been fully established and positive rates of PSA vary greatly depending on reports $[5,38,39]$. It may be useful to verify by combining quantitative methods such as time resolved immunofluorometric assay or Mass Spectrometry-Based Proteomic Profiling $[40,41]$. In the present study, we found a negative correlation between sPSA and Ki67 in postmenopausal MBC (Table 3, Fig. 2). In the majority of 

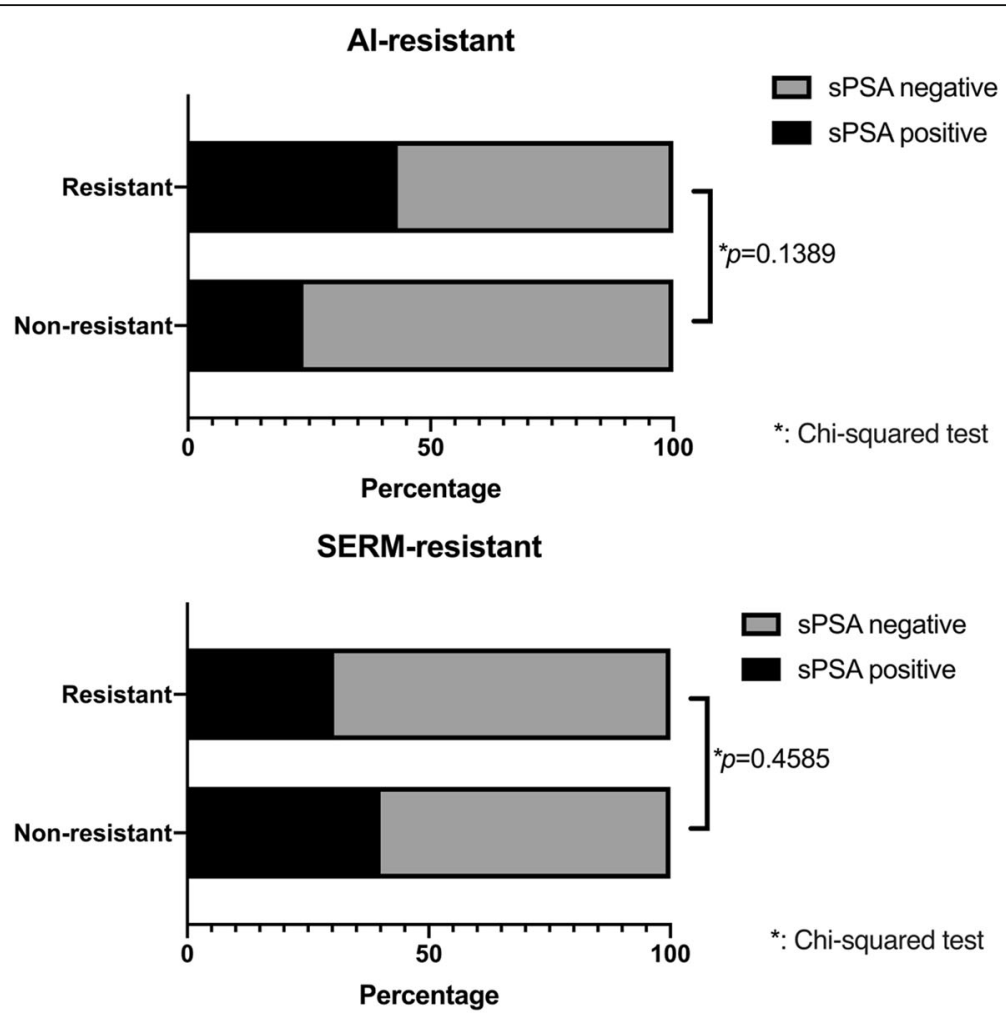

SERD-resistant

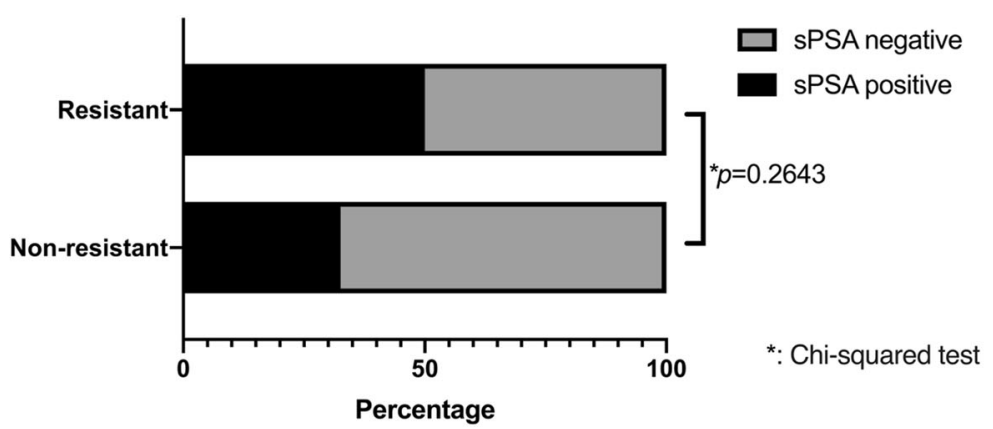

Fig. 3 Difference in sPSA values due to previous endocrine therapy $(n=58)$. The $X$ axis shows sPSA detection rate. The difference between two groups were analyzed by Chi-squared test. Values of $p<0.05$ were considered statistically significant

Table 4 Difference in sPSA detection rate due to previous endocrine therapy $(n=58)$

\begin{tabular}{|c|c|c|c|c|}
\hline & $n$ & sPSA positive (\%) & sPSA negative (\%) & $p$ value \\
\hline \multicolumn{4}{|c|}{ Aromatase inhibitor resistance } & 0.1389 \\
\hline Yes & 37 & $16(43.2)$ & $21(56.8)$ & \\
\hline No & 21 & $5(23.8)$ & $16(76.2)$ & \\
\hline \multicolumn{4}{|c|}{ SERM resistance } & 0.4584 \\
\hline Yes & 23 & $7(30.4)$ & $16(69.6)$ & \\
\hline No & 35 & $14(40.0)$ & $21(60.0)$ & \\
\hline \multicolumn{4}{|c|}{ SERD resistance } & 0.2643 \\
\hline Yes & 12 & $6(50.0)$ & $6(50.0)$ & \\
\hline No & 46 & 15 (32.6) & 31 (67.4) & \\
\hline
\end{tabular}

studies, AR expression in ER-positive tumors or TNBCs has been associated with favorable characteristics including lower Ki67 positivity [42-44]. Therefore, assuming that SPSA reflects the function of AR in the tumor, this result is consistent with our result. Next, we focused on sPSA values in various endocrine therapy-resistant breast cancers. As mentioned above, it has been suggested that tumors may shift their dependence from ER to $\mathrm{AR}$ as a possible endocrine therapy resistance mechanism [4, 9-11]. We hypothesized that if sPSA acts as a readout of AR signaling in tumors, then sPSA levels might change during endocrine therapy. Therefore, we compared sPSA levels in patients with resistance to endocrine therapies. It is known that the androgen 


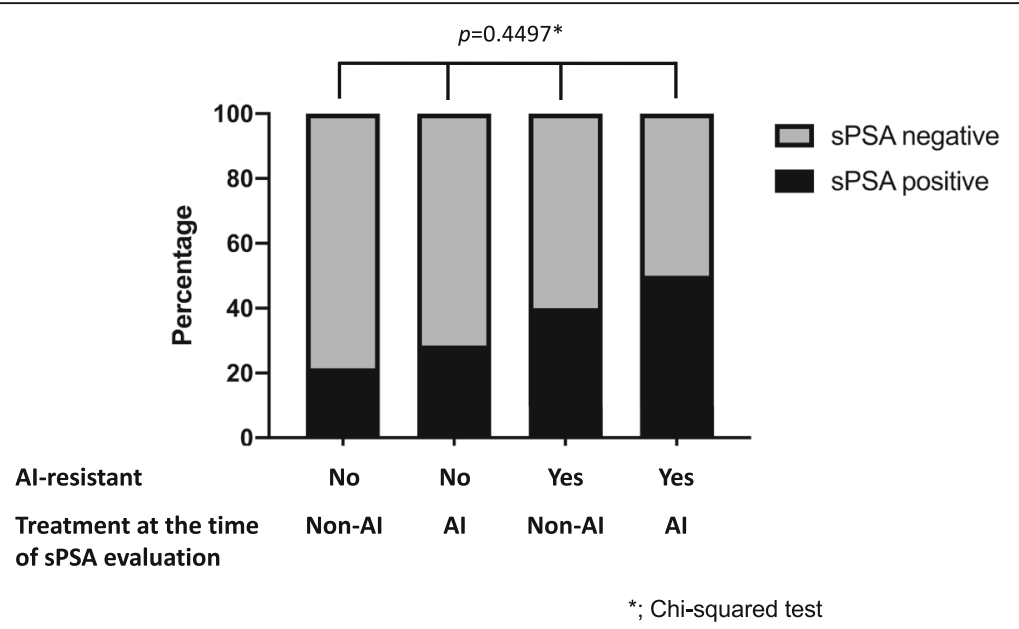

Fig. 4 Difference in SPSA values due to treatment and Al resistance property $(n=58)$. The vertical axis shows sPSA detection rate. Chi-squared tests were used for comparison of SPSA detection rate among multiple groups. Values of $p<0.05$ were considered statistically significant

concentration in the tumor can increase with AI treatment [45]. However, in our analysis, sPSA tended to be higher in AI-resistant cases compared with non-AI resistant cases, regardless of whether patients were on AI therapy at the time of the blood sample collection (Fig. 4. Additional file 1 Figure S1). These findings suggest that elevation of sPSA was not simply caused by increase in androgen following AI treatment and that some of the ER-positive post-menopausal MBC may switch from ER-dependent to AR-dependent as a mechanism of resistance to traditional endocrine therapies, particularly AI. All of the above results show that sPSA may reflect tumor biological properties, including androgen signals and changes associated with treatment in post-menopausal breast cancer.

In metastatic or recurrent breast cancer, treatment selection is made based on the biological information obtained from primary lesion; however, after treatment, tumor biology evolves during the course of treatment. However, it is difficult to take a biopsy of metastatic lesions frequently. Serum PSA can be assessed by blood exam which is a minimally invasive examination. Based on the result of present study, we hypothesize that PSA may be useful for effective treatment selection, especially for AR-targeting therapies in post-menopausal breast cancer patients. However, because this analysis is an observational study, it is difficult to verify whether sPSA reflects AR signal of the tumor in a strict sense. Therefore, further analysis using in-vitro and in-vivo models, including interventional clinical studies using ARtargeted therapies, should be performed.

\section{Conclusion}

Tumor derived sPSA was detectable in a portion of postmenopausal breast cancer patients (27.4\%). Serum PSA levels were weakly associated with serum testosterone levels and AR positivity in primary tumors suggesting that sPSA may reflect some tumor biological properties including androgen signals in post-menopausal breast cancer. Thus, serum PSA may be useful for identifying patients with tumors expressing active AR.

\section{Supplementary information}

Supplementary information accompanies this paper at https://doi.org/10. 1186/s12885-019-6256-2.

Additional file 1: Table S1. Preliminary experiment for selection of sPSA measurement kit $(n=10)$. Table S2. sPSA values in breast cancer patients and healthy controls. Table S3. sPSA values in post-menopausal breast cancer patients ( $n=117)$. Table S4. Difference in SPSA values due to previous endocrine therapy $(n=58)$.

Additional file 2: Figure S1. (PDF 42 kb)

\section{Abbreviations}

Al: aromatase inhibitor; AR: androgen receptor; CLEIA: chemiluminescent enzyme immunoassay; ER: estrogen receptor a; FISH: fluorescence in situ hybridization; HER2: human epidermal growth factor receptor 2; KLK3: kallikrein related peptidase 3; MBC: metastatic breast cancer; PgR: progesterone receptor; PSA: prostate specific antigen; SERDs: Selective estrogen receptor degraders; SERMs: Selective estrogen receptor modulators; sPSA: serum PSA; TNBC: Triple negative breast cancer

\section{Acknowledgments}

We thank Jessica Christenson, Jennifer K Richer (Department of Pathology, Colorado University, CO, USA) and Anthony D. Elias (Division of Medical Oncology, Colorado University, CO, USA) for discussions, helpful suggestions and English proof reading

\section{Authors' contributions}

$\mathrm{TH}$ led conception and design, acquired the necessary data, led the statistical analysis and interpretation of data, drafted the manuscript, and revised content based on feedback. Kl assisted with interpretation of data and provided critical revision of drafts. SH, HM and TN performed the experimental work. KO, HW, MK, SS and HK has substantial contributions to the acquisition of necessary data. All of the authors read and approved the final version of this manuscript. 


\section{Funding}

This research did not receive any specific grant from any funding agency in the public, commercial or not-for-profit sector.

\section{Availability of data and materials}

The datasets analyzed during the current study are not publicly available due to no suitable repository but are available from the corresponding author on reasonable request.

\section{Ethics approval and consent to participate}

All procedures performed in this study involving human participants were conducted with approval of the Suwa Red Cross Hospital ethics committee (reference number: 29-40) in accordance with the ethical standards of the institutional research committee and with the 1964 Helsinki declaration and its later amendments. Written informed consent was obtained from all participants for protocols including blood collection, reviewing case records and use of archival sample.

\section{Consent for publication}

Not Applicable.

\section{Competing interests}

All of the authors declare that there is no conflict of interest that could be perceived as prejudicing the impartiality of the research reported.

\section{Author details}

1 Department of Breast and Endocrine Surgery, Suwa Red Cross Hospital, 5-11-50, Kogan-dori, Suwa, Nagano 392-8510, Japan. ²Division of Breast and Endocrine Surgery, Department of Surgery, Shinshu University School of Medicine, 3-1-1 Asahi, Matsumoto, Nagano 390-8621, Japan. ${ }^{3}$ Department of Pathology, University of Colorado Anschutz Medical Campus, 12800 East 19th Avenue, Aurora, CO 80045, USA. ${ }^{4}$ Department of Diagnostic Pathology, Suwa Red Cross Hospital, 5-11-50, Kogan-dori, Suwa, Nagano 392-8510, Japan. ${ }^{5}$ Department of Laboratory Medicine, Suwa Red Cross Hospital, 5-11-50, Kogan-dori, Suwa, Nagano 392-8510, Japan. ${ }^{6}$ Medical checkup Center, Suwa Red Cross Hospital, 5-11-50, Kogan-dori, Suwa, Nagano 392-8510, Japan. ${ }^{7}$ Department of Surgery, Suwa Central Hospital, 4300, Tamagawa, Chino, Nagano 391-8503, Japan. ${ }^{8}$ Department of Surgery, Okaya City Hospital, 4-11-33, Hon-machi, Okaya, Nagano 394-8512, Japan. ${ }^{9}$ Koyama Breast and Thyroid Clinic, 1-2557-1, Jonan, Suwa, Nagano 392-0017, Japan.

\section{Received: 28 February 2019 Accepted: 14 October 2019}

\section{Published online: 29 October 2019}

\section{References}

1. Clarke R, Leonessa F, Welch JN, Skaar TC. Cellular and molecular pharmacology of antiestrogen action and resistance. Pharmacol Rev. 2001; 53(1):25-71.

2. Yamashita $\mathrm{H}$. Current research topics in endocrine therapy for breast cancer. Int J Clin Oncol. 2008;13(5):380-3. https://doi.org/10.1007/s10147-008-0818-7.

3. Libson S, Lippman M. A review of clinical aspects of breast cancer. International review of psychiatry (Abingdon, England). 2014;26(1):4-15. https://doi.org/10.3109/09540261.2013.852971.

4. Basile D, Cinausero M, lacono D, Pelizzari G, Bonotto M, Vitale MG, Gerratana L, Puglisi F. Androgen receptor in estrogen receptor positive breast cancer: beyond expression. Cancer Treat Rev. 2017;61:15-22. https://doi.org/10. 1016/j.ctrv.2017.09.006.

5. Fujii R, Hanamura T, Suzuki T, Gohno T, Shibahara Y, Niwa T, Yamaguchi Y, Ohnuki K, Kakugawa Y, Hirakawa H, Ishida T, Sasano H, Ohuchi N, Hayashi S. Increased androgen receptor activity and cell proliferation in aromatase inhibitor-resistant breast carcinoma. The journal of steroid biochemistry and molecular biology 144 Pt B:513-522. 2014. https://doi.org/10.1016/j.jsbmb. 2014.08.019.

6. Hanamura T, Hayashi SI. Overcoming aromatase inhibitor resistance in breast cancer: possible mechanisms and clinical applications. Breast cancer. Japan: Tokyo; 2017. https://doi.org/10.1007/s12282-017-0772-1.

7. Hayashi S, Kimura M. Mechanisms of hormonal therapy resistance in breast cancer. Int J Clin Oncol. 2015;20(2):262-7. https://doi.org/10.1007/s10147015-0788-5.

8. De Amicis F, Thirugnansampanthan J, Cui Y, Selever J, Beyer A, Parra I, Weigel NL, Herynk MH, Tsimelzon A, Lewis MT, Chamness GC, Hilsenbeck
SG, Ando S, Fuqua SA. Androgen receptor overexpression induces tamoxifen resistance in human breast cancer cells. Breast Cancer Res Treat. 2010;121(1):1-11. https://doi.org/10.1007/s10549-009-0436-8.

9. Cochrane DR, Bernales S, Jacobsen BM, Cittelly DM, Howe EN, D'Amato NC, Spoelstra NS, Edgerton SM, Jean A, Guerrero J, Gomez F, Medicherla S, Alfaro IE, McCullagh E, Jedlicka P, Torkko KC, Thor AD, Elias AD, Protter AA, Richer JK. Role of the androgen receptor in breast cancer and preclinical analysis of enzalutamide. Breast cancer research : BCR. 2014;16(1):R7. https:// doi.org/10.1186/bcr3599.

10. D'Amato NC, Gordon MA, Babbs B, Spoelstra NS, Carson Butterfield KT, Torkko KC, Phan VT, Barton VN, Rogers TJ, Sartorius CA, Elias A, Gertz J, Jacobsen BM, Richer JK. Cooperative dynamics of AR and ER activity in breast Cancer. Molecular cancer research : MCR. 2016;14(11):1054-67. https://doi.org/10.1158/1541-7786.mcr-16-0167.

11. Hickey TE, Robinson JL, Carroll JS, Tilley WD. Minireview: the androgen receptor in breast tissues: growth inhibitor, tumor suppressor, oncogene? Molecular endocrinology (Baltimore, Md). 2012;26(8):1252-67. https://doi. org/10.1210/me.2012-1107.

12. Lehmann $B D$, Bauer JA, Chen $X$, Sanders $M E$, Chakravarthy $A B$, Shyr $Y$, Pietenpol JA. Identification of human triple-negative breast cancer subtypes and preclinical models for selection of targeted therapies. J Clin Invest. 2011;121(7):2750-67. https://doi.org/10.1172/jci45014.

13. Ni M, Chen Y, Lim E, Wimberly H, Bailey ST, Imai Y, Rimm DL, Liu XS, Brown M. Targeting androgen receptor in estrogen receptor-negative breast cancer. Cancer Cell. 2011;20(1):119-31. https://doi.org/10.1016/j.ccr.2011.05.026.

14. Barton VN, D'Amato NC, Gordon MA, Lind HT, Spoelstra NS, Babbs BL, Heinz RE, Elias A, Jedlicka P, Jacobsen BM, Richer JK. Multiple molecular subtypes of triple-negative breast cancer critically rely on androgen receptor and respond to enzalutamide in vivo. Mol Cancer Ther. 2015;14(3):769-78. https://doi.org/10.1158/1535-7163.mct-14-0926.

15. Barton VN, Christenson JL, Gordon MA, Greene LI, Rogers TJ, Butterfield K, Babbs B, Spoelstra NS, D'Amato NC, Elias A, Richer JK. Androgen receptor supports an Anchorage-independent, Cancer stem cell-like population in triple-negative breast Cancer. Cancer Res. 2017;77(13):3455-66. https://doi. org/10.1158/0008-5472.can-16-3240.

16. Haffty BG, Yang Q, Reiss M, Kearney T, Higgins SA, Weidhaas J, Harris L, Hait W, Toppmeyer D. Locoregional relapse and distant metastasis in conservatively managed triple negative early-stage breast cancer. J Clin Oncol. 2006;24(36):5652-7. https://doi.org/10.1200/jco.2006.06.5664.

17. Tan DS, Marchio C, Jones RL, Savage K, Smith IE, Dowsett M, Reis-Filho JS (2008) Triple negative breast cancer: molecular profiling and prognostic impact in adjuvant anthracycline-treated patients. Breast Cancer Res Treat 111 (1):27-44. doi:https://doi.org/10.1007/s10549-007-9756-8.

18. Barton VN, D'Amato NC, Gordon MA, Christenson JL, Elias A, Richer JK. Androgen receptor biology in triple negative breast Cancer: a case for classification as AR+ or quadruple negative disease. Hormones and cancer. 2015;6(5-6):206-13. https://doi.org/10.1007/s12672-015-0232-3.

19. Kono M, Fujii T, Lim B, Karuturi MS, Tripathy D, Ueno NT. Androgen receptor function and androgen receptor-targeted therapies in breast Cancer: a review. JAMA oncology. 2017;3(9):1266-73. https://doi.org/10.1001/ jamaoncol.2016.4975.

20. Mina A, Yoder R, Sharma P. Targeting the androgen receptor in triplenegative breast cancer: current perspectives. OncoTargets and therapy. 2017;10:4675-85. https://doi.org/10.2147/ott.s126051.

21. Cleutjens KB, van Eekelen CC, van der Korput HA, Brinkmann AO, Trapman J. Two androgen response regions cooperate in steroid hormone regulated activity of the prostate-specific antigen promoter. J Biol Chem. 1996;271(11): 6379-88.

22. Fujita K, Nonomura N. Role of androgen receptor in prostate Cancer: a review. The world journal of men's health. 2018. https://doi.org/10.5534/ wjmh. 180040 .

23. Perez-Ibave DC, Burciaga-Flores CH, Elizondo-Riojas MA. Prostate-specific antigen (PSA) as a possible biomarker in non-prostatic cancer: a review. Cancer Epidemiol. 2018;54:48-55. https://doi.org/10.1016/j.canep.2018.03.009.

24. Rao AR, Motiwala HG, Karim OM. The discovery of prostate-specific antigen. BJU Int. 2008;101(1):5-10. https://doi.org/10.1111/j.1464-410X.2007.07138.X.

25. Armbruster DA. Prostate-specific antigen: biochemistry, analytical methods, and clinical application. Clin Chem. 1993;39(2):181-95.

26. Musrap N, Diamandis EP. Prostate-specific antigen as a marker of Hyperandrogenism in women and its implications for Antidoping. Clin Chem. 2016;62(8):1066-74. https://doi.org/10.1373/clinchem.2016.256198. 
27. Black MH, Giai M, Ponzone R, Sismondi P, Yu H, Diamandis EP. Serum total and free prostate-specific antigen for breast cancer diagnosis in women. Clin Cancer Res. 2000;6(2):467-73.

28. Hautmann S, Huland E, Grupp C, Haese A, Huland H. Super-sensitive prostate-specific antigen (PSA) in serum of women with benign breast disease or breast cancer. Anticancer Res. 2000;20(3b):2151-4.

29. Cserni G, Chmielik E, Cserni B, Tot T. The new TNM-based staging of breast cancer. Virchows Arch. 2018;472(5):697-703. https://doi.org/10.1007/s00428018-2301-9.

30. Hammond ME, Hayes DF, Dowsett M, Allred DC, Hagerty KL, Badve S, Fitzgibbons PL, Francis G, Goldstein NS, Hayes M, Hicks DG, Lester S, Love R, Mangu PB, McShane L, Miller K, Osborne CK, Paik S, Perlmutter J, Rhodes A, Sasano H, Schwartz JN, Sweep FC, Taube S, Torlakovic EE, Valenstein P, Viale G, Visscher D, Wheeler T, Williams RB, Wittliff JL, Wolff AC. American Society of Clinical Oncology/College of American Pathologists guideline recommendations for immunohistochemical testing of estrogen and progesterone receptors in breast cancer (unabridged version). Arch Pathol Lab Med. 2010;134(7):e48-72. https:// doi.org/10.1043/1543-2165-134.7.e48.

31. Wolff AC, Hammond ME, Hicks DG, Dowsett M, McShane LM, Allison KH, Allred DC, Bartlett JM, Bilous M, Fitzgibbons P, Hanna W, Jenkins RB, Mangu PB, Paik S, Perez EA, Press MF, Spears PA, Vance GH, Viale G, Hayes DF. Recommendations for human epidermal growth factor receptor 2 testing in breast cancer: American Society of Clinical Oncology/College of American Pathologists clinical practice guideline update. J Clin Oncol. 2013;31(31): 3997-4013. https://doi.org/10.1200/jco.2013.50.9984.

32. Coates AS, Winer EP, Goldhirsch A, Gelber RD, Gnant M, Piccart-Gebhart M, Thurlimann B, Senn HJ. Tailoring therapies--improving the management of early breast cancer: St Gallen international expert consensus on the primary therapy of early breast Cancer 2015. Ann Oncol. 2015;26(8):1533-46. https:// doi.org/10.1093/annonc/mdv221.

33. Tsuda H, Akiyama F, Kurosumi M, Sakamoto G, Watanabe T. The efficacy and limitations of repeated slide conferences for improving interobserver agreement when judging nuclear atypia of breast cancer. The Japan National Surgical Adjuvant Study of breast Cancer (NSAS-BC) pathology section. Jpn J Clin Oncol. 1999;29(2):68-73.

34. Tsuda H, Akiyama F, Kurosumi M, Sakamoto G, Watanabe T. Establishment of histological criteria for high-risk node-negative breast carcinoma for a multi-institutional randomized clinical trial of adjuvant therapy. Japan National Surgical Adjuvant Study of breast Cancer (NSAS-BC) pathology section. Jpn J Clin Oncol. 1998;28(8):486-91.

35. Melegos DN, Diamandis EP. Is prostate-specific antigen present in female serum? Clin Chem. 1998;44(3):691-2.

36. Mashkoor FC, Al-Asadi JN, Al-Naama LM. Serum level of prostate-specific antigen (PSA) in women with breast cancer. Cancer Epidemiol. 2013;37(5): 613-8. https://doi.org/10.1016/j.canep.2013.06.009.

37. Razavi SHE, Ghajarzadeh M, Abdollahi A, Taran L, Shoar S, Omranipour R. Is serum prostate-specific antigen a diagnostic marker for benign and malignant breast tumors in women. Maedica. 2015;10(2):107-11.

38. Alanen KA, Kuopio T, Koskinen PJ, Nevalainen TJ. Immunohistochemical labelling for prostate specific antigen in non-prostatic tissues. Pathol Res Pract. 1996;192(3):233-7. https://doi.org/10.1016/s0344-0338(96)80226-3.

39. Howarth DJ, Aronson IB, Diamandis EP. Immunohistochemical localization of prostate-specific antigen in benign and malignant breast tissues. $\mathrm{Br} \mathrm{J}$ Cancer. 1997;75(11):1646-51. https://doi.org/10.1038/bjc.1997.280.

40. Flores-Morales A, Iglesias-Gato D. Quantitative mass spectrometry-based proteomic profiling for precision medicine in prostate Cancer. Front Oncol. 2017;7:267. https://doi.org/10.3389/fonc.2017.00267.

41. Yu H, Diamandis EP, Sutherland DJ. Immunoreactive prostate-specific antigen levels in female and male breast tumors and its association with steroid hormone receptors and patient age. Clin Biochem. 1994;27(2):75-9. https://doi.org/10.1016/0009-9120(94)90015-9.

42. McNamara KM, Yoda T, Miki Y, Chanplakorn N, Wongwaisayawan S, Incharoen P, Kongdan Y, Wang L, Takagi K, Mayu T, Nakamura Y, Suzuki T, Nemoto N, Miyashita M, Tamaki K, Ishida T, Ohuchi N, Sasano H. Androgenic pathway in triple negative invasive ductal tumors: its correlation with tumor cell proliferation. Cancer Sci. 2013;104(5):639-46. https://doi.org/10.1111/cas.12121.

43. Mrklic I, Pogorelic Z, Capkun V, Tomic S. Expression of androgen receptors in triple negative breast carcinomas. Acta Histochem. 2013;115(4):344-8. https://doi.org/10.1016/j.acthis.2012.09.006.
44. McNamara KM, Moore NL, Hickey TE, Sasano H, Tilley WD. Complexities of androgen receptor signalling in breast cancer. Endocr Relat Cancer. 2014; 21(4):T161-81. https://doi.org/10.1530/erc-14-0243.

45. Takagi K, Miki Y, Nagasaki S, Hirakawa H, Onodera Y, Akahira J, Ishida T, Watanabe M, Kimijima I, Hayashi S, Sasano H, Suzuki T. Increased intratumoral androgens in human breast carcinoma following aromatase inhibitor exemestane treatment. Endocr Relat Cancer. 2010;17(2):415-30. https://doi.org/10.1677/ERC-09-0257.

\section{Publisher's Note}

Springer Nature remains neutral with regard to jurisdictional claims in published maps and institutional affiliations.

\section{Ready to submit your research? Choose BMC and benefit from:}

- fast, convenient online submission

- thorough peer review by experienced researchers in your field

- rapid publication on acceptance

- support for research data, including large and complex data types

- gold Open Access which fosters wider collaboration and increased citations

- maximum visibility for your research: over $100 \mathrm{M}$ website views per year

At BMC, research is always in progress.

Learn more biomedcentral.com/submissions 